\title{
Moral Dilemmas in Foster Care Due to Religious Differences Between Birth Parents, Foster Parents, and Foster Children
}

\author{
Diana D. van Bergen ${ }^{1}$ (D) Sawitri Saharso ${ }^{2,3} \cdot$ Clementine J. Degener $^{4} \cdot$ Brenda E. Bartelink $^{1} \cdot$ Johan Vanderfaeillie $^{5}$
}

Accepted: 30 December 2021

(c) The Author(s) 2022

\begin{abstract}
Many ethnoreligious-minority foster children in several western countries, including the Netherlands, are placed and permanently live with ethnically and religiously non-matched foster families (i.e., in trans-religious foster care). We examine whether and which moral dilemmas exist around the issue of how religion should be weighted in trans-religious foster care to provide ethnoreligious-minority foster children with healthy identity development. We applied a thematic analysis to 17 qualitative interviews (seven foster parent/foster child dyads and three foster parents) taken from two pre-existing datasets. We retrieved five moral dilemmas in trans-religious foster care placements, which are discussed in relation to the following ethical arguments: (1) pressure from birth parents and parents of foster children to abide by their religious praxis; (2) objections of the foster family to the faith of the birth family; (3) a switch to the faith of the foster family by the foster child; (4) challenges to the religious identity searches of foster children due to ethnoreligious boundary drawing between majority and minority groups; and (5) the impact of religious traditions on the bodily integrity of foster children. We argue that it is in the best interest of foster children to have a foster family who, when making (some) religious choices on their behalf, is sensitive to the particular child and their developing identity with regard to their religious ideas and beliefs. Foster families need support regarding religious reflection and religious self-determinism in their foster children.
\end{abstract}

Keywords Religion $\cdot$ Foster care $\cdot$ Moral dilemmas $\cdot$ Minority children

Diana D. van Bergen

d.d.van.bergen@rug.nl

Sawitri Saharso

S.Saharso@uvh.nl

Clementine J. Degener

c.j.degener@hr.nl

Brenda E. Bartelink

b.e.bartelink@rug.nl

Johan Vanderfaeillie

johan.vanderfaeillie@vub.be

1 Department of Education at Groningen University, Faculty of Behavioral and Social Sciences, Grote Kruisstraat 2/1, 9712 TS Groningen, The Netherlands

2 VU University Amsterdam, Amsterdam, The Netherlands

3 University of Humanistic Studies, Kromme Nieuwegracht 29, 3512 HD Utrecht, The Netherlands

4 Rotterdam University of Applied Sciences, museumpark 40, 3015 CX Rotterdam, The Netherlands

5 Vrije Universiteit Brussel, Pleinlaan 2, 1050 Brussels, Belgium

\section{Religious Diversity and Fostercare}

Over the past decades, due to immigration and the secularization of ethnic majority groups (Martin, 2017), many Western European countries have become religiously and ethnically diverse nations (Becci et al., 2017). This diversity has important implications for children and youth who grow up in these nations (Bagci \& Rutland, 2020). In particular, it raises questions for ethnoreligious-minority youth who do not seem to have an optimal start for their psychosocial development, for example because they are confronted with a severely adverse family context (Degener et al., 2021). Sometimes, an adverse family context results in an out-ofhome placement, such as a foster care placement.

In many European and North American countries, ethnoreligious-minority children are overrepresented among foster children. Moreover, in many western nations, foster families have different religious ties than the foster children and their families (Skivenes et al., 2014). However, transreligious placements have received limited attention in foster care studies (but see Jackson et al., 2010; Pitcher \& Jaffar, 
2018). An increasing number of studies on trans-ethnic placements in foster care have found how the discontinuity of the ethnic roots of foster children in such placements can create multiple challenges for their psychosocial development and ethnic identity development (Degener et al., 2021; White et al., 2008). Considering the overlap between ethnic and religious minority statuses, it can be assumed that transreligious placements may hinder religious identity development and thus be undesirable. However, policymaking for youth care, in this case foster care, should also have clear empirical foundations (Allen et al, 2018) in which the potential pros and cons of trans-religious placements of foster children are carefully unpacked. This study hereby primarily contributes to discussions among academics and professionals about the interests that may be at stake in trans-religious placements from the perspective of the child as well as foster families. It will compare theoretical and ethical arguments with the lived experiences of religiously non-matched foster children, because what may seem to be theoretically sound arguments in the best interest of the foster child regarding religious development need to be carefully weighed against the actual experiences of foster children in care practices (Reimer \& Schafer, 2015; Strolin-Goltzman et al., 2010). We chose the Netherlands as a context for the study, as it exemplifies the high frequencies of trans-religious placements of foster children (Day \& Bellaart, 2015).

Secure identity formation is among the most critical tasks for young people during adolescence and is likely to result in healthier psychosocial development and smoother transitioning to adulthood (Arnett, 2015). For foster youth, developing a strong personal and social (including religious or ethnic) identity may be challenging, since their lives are often characterized by multiple vulnerabilities due to past trauma, neglect, or abuse (Tyrell et al., 2019). Studies on the ethnic identity of trans-ethnically placed foster children show ethnic identity losses for such children due to disconnection or interruption of their (primary) ethnic socialization network, which creates affronts to their psychological wellbeing (Degener et al., 2020). This finding suggests that religiously non-matched foster care placements may also affect children's identity through relationship losses and/or new socializing contexts.

In foster care, we define a trans-religious (or religiously non-matched) placement as one in which a child is placed in a foster family that adheres to a different religious belief and praxis from the birth parents. It could also be the placement of a child from a non-religious family in a religious foster family, or vice versa. We expect that a placement in a religiously non-matched foster care family may create confusion, questions, or conflict for children, particularly during adolescence, as identity explorations, reflections, and identity commitment are intensified for individuals during this period. When children live in a family context that abides by a religious faith, set of values, or religious lifestyle that potentially conflicts with the religious convictions and praxis of their birth family, these identity searches or conflicts may be particularly challenging. The research question we address in this study is whether and which moral dilemmas exist around the issue of how religion should be weighted in trans religious foster care in order to provide foster children with healthy identity development? Throughout the study, although we address the rights and interests of several sources (birth parents, foster parents), we prioritize the interests of foster children.

First, we discuss which interests and rights are at stake in non-matched foster care placements, paying particular attention to challenges around the freedom of religion for children, as they are our primary group of interest. Second, we discuss the lived experiences of foster children in regard to the role and impact of religion in their lives, based on a number of cases. Once we determine whether a non-matched foster care placement is lived as a (substantial) challenge by the foster child on the basis of empirically informed analyses, we can shift back to the ethical perspectives in our discussion, in which we weigh the role and impact of religion on foster children's wellbeing. In conclusion, we formulate recommendations for policies regarding foster care.

\section{Religion in Young People's Lives}

The religious identity of young individuals who have a faith is often a relevant aspect of their wider identity and is informed by what is considered "formal" religion, alongside their everyday faith based practices. Formal religion can be considered as a knowledge system which offers an ideological base that legitimizes or motivates moral beliefs, behavioral norms, and values (Vermeer, 2014). Thus, religion brings order and logic to the world around believers as well as to their place within it (Bell, 2009). In addition to the grand schemes of formal religions, religion is "lived" and experienced by individuals, who must negotiate it against the other normative frameworks and worldviews they encounter (Ammerman, 2007; Bender, 2012; McGuire, 2008). In everyday life, religion is entangled with the personal and social dimensions of one's identity, for example by understanding how a believer is connected to a community of fellow believers or how religion is enmeshed in family relations (Knibbe $\&$ Kupari, 2020). Young people's positioning in social relationships, shaped by generation, ethnicity, and class, may also influence their religious identification. In the context of foster care, we therefore need to consider the interests of those parties directly involved in foster care placement, particularly the children, but also the birth parents and foster parents. 


\section{Religious Differences Between Foster Children, Foster Parents, and Birth Parents: Moral Dilemmas}

Foster children have the right to be able to adopt the religion of their choice, as formulated in Article 14 of the Covenant of the Civil and Political Rights of Children (CCPRC) (see Kilkelly, 2014). Article 14 of the CCPRC (Kilkelly, 2014) also states that children's right to adopt a religion of their choice should be based on their age or maturity. Many scholars emphasize that, as children mature into adolescence, their capability for rational reflective decision making, including regarding their religious identities, will progress. Although children vary in when they reach sufficient competency (i.e., understanding and intelligence) to decide on religious matters, few experts would set this age below early adolescence (10-12 years old). We have reasons to doubt whether, in practice, this right, formulated in Article 14 of the CCPRC (Kilkelly, 2014), is sufficiently protected for trans-religiously placed foster children. Children in foster care may have experienced pressure before their religious identities gradually shifted alongside their repositioning in foster family and birth family relationships (Pitcher \& Jaffar, 2018). Consequently, various potentially conflicting rights and interests of the child may become compromised in trans-religious foster placements.

First, it is plausible that religious-minority children and non-religious foster children would need to nurture and maintain their religion for a sense of authenticity: the feeling that they are staying true to themselves (Clayton, 2019; Smith, 1996). Continuity of religious roots can enable a sense of coherence, worthiness, and wellbeing (Jackson et al., 2010; Scott et al., 2006). Arguably, nurturing one's religion without one's religious community is difficult. Article 20 of the Children's Human Rights Convention (Convention on the rights of the child, 1989) states that when out-of-home placement is necessary, the desirability of continuity in the religious background of the child must be considered. Article 30 of the Convention on the rights of the child (1989) grants children from religious-, ethnic-, and linguistic-minority groups the right to practice their religion, experience their culture, and use their language. A related argument is that foster children may feel alienated from their parents, families, and religious communities when they grow up with different (possibly contrasting) religious views than those of the birth family (Smith, 1996). This situation may create tensions in their relationship with their parents and (extended) family, while it is generally acknowledged that maintaining or creating healthy parent-child or family-child relationships is important for adolescents' wellbeing (Arnett,
2015). A trans-religious foster placement may thus also threaten the right to family life.

Furthermore, children's right to autonomy (Hannan, 2019) may be jeopardized by placement in a foster family of a different religion. This is obvious, of course, if foster parents aim for their foster child to adopt their religion, but the foster child's right to autonomy may also be infringed as an unintended effect of the non-matching placement. Children are always born within a family that practices a specific religion or has a certain worldview, whether secular or spiritual. In a liberal society, when children mature, they are expected to have the freedom to decide what values they want to live by for themselves (Hannan, 2019).

Yet, as Will Kymlicka (1995) has argued, for people from minority cultures and religions to have a real choice, they need to have access to their religious culture as a full context of choice. Visible behavioral models seem key to creating such a context, since studies have shown that intergenerational transmission of religious beliefs is more likely to occur if children are shown concrete daily religious examples (Vermeer, 2014). Underpinning social learning theory (Bandura \& McClelland, 1977), observation and imitation of what educators offer regarding religion is key in religious socialization, especially in younger children. However, foster families with a different religion or worldview than their foster children will continue their religious praxis as they did before the arrival of those children. If foster children see only performances of religious practices and attendance in the religious tradition of their foster family, it becomes more difficult for them to choose to abide by another religion, for instance that of their birth parents. Thus, living in a foster family that practices a different religion or no religion at all, while not seeing one's original religious culture similarly endorsed, creates an unbalanced context of choice for foster children (Pitcher \& Jaffar, 2018).

While there are arguments against placing children in a foster family of another religion, there is also an argument for doing so. Arguably, if a religiously matched foster family is unavailable or not considered to be suitable, an affectionate and stable religiously non-matched family may be preferred over a placement in a residential home or a temporary placement in foster care while waiting for a religious match (Smith, 1996; Zeijlmans et al., 2017). Rushton and Minnis (2008) found that multiple placements, as well as residential care (compared to foster care), are associated with decreased psychosocial health. Hence, whether it is better for the child's wellbeing to be quickly placed in a religiously non-matching foster family or stay longer in residential care awaiting a match constitutes a serious moral dilemma with extensive consequences for children.

Next, it is relevant to address birth parents and their take on religion, as in many cases they will remain (partially) 
involved in the lives of their children. Birth parents who have custody have the legal right to make and be involved in decisions about the type of religious education their children receive, even when the latter are placed outside their home (e.g., Universal Declaration of Human Rights (UDHR), Art. 26. 3; CRC, Art. 14. 2; cf. Kilkelly, 2009). Greater emphasis is placed on this right when it concerns children of parents with a religious-minority background, since the protection of ethnoreligious minority groups is also emphasized in the CRC, in Article 30. Jurisprudence in the Netherlandsobserved in court cases around religious diversity and foster care- demonstrates that article 30 of the CRC is interpreted as having access to religion or religious infrastructure rather than the right to full continuity of religious socialization from birth parents (Jonker et al., 2015). An important ethical perspective which has influenced the legal framework in the Netherlands (and beyond) around religion and foster care in this respect, is the notion that birth parents should be able to exercise influence on the type of religious knowledge and practices that their child is introduced to. Simultaneously, the birth parents cannot determine the extent to which the child will submit to religious ideas and practices.

In addition, the foster parents' religious interests are relevant here, as their behavior will influence foster children's development. Foster parents have the right to be able to pursue their own religious beliefs (and praxis), even when a foster child enters their home (e.g., UDHR, Article 18). When foster children are exempted from attending a place of worship, such as a church, this may create tensions with their biological children. Their biological children may start questioning the need for the religious praxis required by the parents, complicating parents' ability to perform their religious socialization ideas.

\section{Method}

\section{The Context of the Current Study: Foster Care in the Netherlands and the Dutch Religious Landscape}

In 2019, there were 23,272 minors in family foster care in the Netherlands out of a Dutch youth population (less than 18 years old) of approximately 3.5 million. In the same year, about half the foster children $(52 \%)$ were in kinship foster care, and $45 \%$ of foster care placements lasted longer than 12 months. Most longer-term foster care placements in the Netherlands become permanent placements, since birth parents are perceived to be unable to provide a healthy psychosocial environment for children. However, a reunification can still be decided on at any time during long-term foster care, as both severance of parental rights and the adoption of a child in care are not very common in the Netherlands.

Examining the religious landscape of the Netherlands shows that it is among those western nations that have seen decreasing membership of mainstream Christian churches alongside increasing religious diversity due to immigration (Kennedy \& Zwemer, 2010; Kregting et al., 2018; Meyer, 2018). Approximately 35\% of the Dutch population is Christian (mainstream/orthodox Protestant as well as Catholic), almost 5\% is Muslim, about $40 \%$ does not see itself as religious, a further $10 \%$ describes itself as spiritual, and $10 \%$ does not know (Netherlands Statistics, 2020). The increasing religious diversity in the Netherlands is also visible in the population of foster children, where children with intersecting ethnic and religious-minority backgrounds are overrepresented (Bellaart \& Day, 2015). Due to the increasing religious heterogeneity of the Dutch population and the difficulties faced by foster care agencies in attracting foster families from a minority-religion background, many foster children live with religiously non-matched foster families (Day \& Bellaart, 2015).

\section{Data and Sampling}

The final sample for this study comprised of 10 cases: seven foster child/foster parent dyads (i.e., 14 interviews) and three interviews with foster parents only. To arrive at the final sample of 17 interviews for the current study, we used two preexisting qualitative datasets (based on interviews). The overall aim of the first dataset (built by the first and third authors, and labelled Roots are Powerful) was to explore the ethnocultural identity development of transculturallyplaced foster children in the Netherlands, and religion was mentioned in multiple cases. The project which produced the first dataset included 16 ethnic minority foster children and ethnic majority foster parent dyads in the Netherlands. The current study used purposeful sampling (Palinkas et al., 2015) and selected cases from the first dataset if they (1) concerned a trans-religious foster care placement and (2) provided informed consent to the request for their archived data to be used for the purpose of this study. This process resulted in six cases from the project which produced the first dataset being used in the current study (five foster parent/foster child dyads and one interview with a foster parent only; hence, 11 interviews).

A second preexisting dataset was built by a group of graduate students studying Social Work, under the supervision of the third author, for the purpose of examining the religious identities of trans-religiously placed foster children. We included four cases from the total 12 cases in the second dataset (three dyadic interviews and one foster 
parent interview), who could be re-contacted and provided informed consent for their data to be used for the current study.

Considering the political sensitivity regarding minority ethnicities and religions, relatively few foster care organizations, professionals, and parents were willing to participate in the study, resulting in a relatively small sample. Nevertheless, considering the paucity of research on foster care and trans-religious placements, we assume the current study can make a contribution.

All participants were placed in non-kinship long-term foster care and had been living with their current foster family for more than half a year. Most (seven out of 10) foster children were ethnic minorities placed in a foster family with an ethnic majority background. One ethnic minority foster child lived with a foster family that had an ethnic minority background, but a different one from the child. One ethnic minority foster child lived with an ethnically and religiously matched family (albeit a less orthodox version of their faith). All ethnic minority children were immigrants of the second or third generation; their backgrounds included Moroccan, Turkish, Somalian, South Asian, Antillean, and Indonesian. Finally, one foster child was a majority Dutch foster child. Three foster families had a Christian faith; in two cases, this concerned an orthodox Protestant faith and in one case, Catholicism. Two foster families had an Islamic faith. Five foster families did not have faith.

All foster children in this sample $(\mathrm{n}=10)$ were between 12 and 17 years old, and the majority $(n=6)$ were in their early adolescence (aged 12-14). Eight birth families of the foster children had a Muslim, Hindu, or Christian faith; two birth families did not identify with a faith. Seven foster children had (some) contact with their parent(s). The age at which the foster children were placed in the foster family where they were living during the interview varied across cases; this could be from infancy up to 12 years old.

\section{Recruitment and Procedure}

In the Roots are Powerful project, the third author found foster care workers working for nine foster care organizations to assist with recruitment. In the smaller project, foster care workers were recruited via two Social Work internship graduate students. Foster care workers notified foster families with an information letter addressed to the foster youth, foster parents, and birth parents (who in some cases had custody). Approximately half of the participants were included via this strategy, and others via snowball sampling, a call on social media, and a foster parent website. Interviews were collected between the fall of 2016 and the winter of 2017 and lasted $45 \mathrm{~min}$ to $1.5 \mathrm{~h}$. The longer interviews tended to be with the foster parents. The study received Institutional Review Board approval in the fall of 2016.

\section{Interview Instruments}

All the interviews were held with a narrative focus and in a semi-structured fashion (Hiles \& Cermák, 2008). Narrative-pointed questions were applied in a way that invited participants to narrate stories and provide examples and illustrations from their lives. The main topics of the interview protocol in the Roots are Powerful project focused on ethnicity and culture regarding foster children's identity. However, without probing by the interviewer, religion was also discussed by the participants included in this study. An example of an interview question was: "Do you feel you belong [to a group, to a community]? Subsequently the interviewer enquired after both ethnic and religious belonging. The interviewer asked follow-up questions that were key to the current study, for example what praxis children adhered to, what meaning it conveyed, if the way religion was addressed in the foster home was different from what they had been used to, and if it was different from how their parents currently practiced their religion. In the second research project that focused primarily on religion, religious shift, and religious identity. An example of a question in the interview with foster parents was: "Did [foster child] ask you any questions to you about your faith? If so, what questions?".

\section{Analysis}

Interviews were transcribed verbatim, and transcripts were first read by the first and third authors in their entirety. The first author then selected relevant transcript excerpts (i.e., fragments regarding religion) and stored them in a Word document; they were then checked for relevance by the second and third author. Subsequently, we used a deductive analytical approach. This means that the second and third authors were instructed by the first author to examine whether and which moral dilemmas existed in the cases related to the excerpts about religion; they were told to remain mindful of a potential lack of such dilemmas. Next, a qualitative thematic analysis (Braun \& Clark, 2006) of all the collected excerpts was performed within and across cases. In this analysis, the first author read the excerpts again and suggested theme identification of five moral dilemma to the second and third author. Again, theme identification concentrated on retrieving significant moral topics present in trans-religious foster care. Through dialogues and discussion between the first three authors, these 
five themes of moral dilemmas related to religion were discussed, interpreted and redefined. When consensus was reached among the first three authors, their interpretations were described in a draft of our result section, which was carefully checked by the fourth and fifth author for coherence and potential bias and adjusted where needed.

\section{Results}

\section{Five Ethical Dilemmas Related to Religious Differences Found in A Sample of Foster Children Placed in A Non-matched Foster Family}

\section{The Interplay of Religious Ties and Pressure from Foster Parents and Birth Parents}

A noted theme among approximately half of the dyads concerned (mild) pressure from parents on their children due to religious differences between them and the foster family. Some of these foster children were explicitly asked by their birth parents to abide by or rejuvenate their involvement with the religious praxis of their birth family. According to their foster parents, some of these foster children seemed to engage in these praxes or traditions not through religious conviction, but not to lose their parental affection. Foster children mentioned that when they visited their parents, their parents seemed to be worried that they would or had lost their religion and would remind them of what was important in their faith or instructed them to adhere to specific praxes they perceived as important. For example, a Muslim parent would remind their child (Hicham) to observe daily prayers, engage in reading religious texts, and start learning or maintaining the language needed for this (such as Arabic for Islamic lessons). An additional example of the impact of pressure from birth parents concerning religion is Navneet. Navneet's birth mother wanted him to follow Hindu dietary restrictions (e.g., no beef or pork). Navneet's foster parents stated that he followed the Hindu dietary restrictions, not because he believed in these religious rationales but because he wanted to protect his foster parents from criticism from his mother that they were inept as parents. From these situations, where foster children are torn between their loyalty toward their parent and their foster family, it can be expected that these challenges are likely to be detrimental to their identity development and feelings of authenticity.
Accommodation of, Versus Objection to, the Faith of the Birth Family by the Foster Family

Minority parents would often make religious requests or give religious reminders to their child or the foster parents. Responses to these requests among foster parents varied. When it concerned a praxis they found relatively easy to accommodate (e.g., dietary restrictions regarding meat) and which did not seem to clash with key components of their faith or worldview, foster parents would mostly try to accommodate these religious requests. However, when there was a request for a religious praxis that foster parents perceived as conflicting with the key features of their faith, they would refrain from accommodating it. An example is the case of the aforementioned Hindu boy, Navneet. Navneet's foster parent stated:

Navneet's mother wants to bring Hindu rituals into our home. Then I say, that's where we draw the line. That is not happening. Across the street from us, there is a Hindu family and they have a Hindu shrine. He is welcome to use theirs, but we don't want it in our home. This is, and will remain, a Christian home.

Furthermore, the foster father obliged Navneet to also attend Christian church each Sunday. In this example the religious interest of the foster parents took priority over and restricted the religious freedom of the foster child. Navneet was not given the freedom to choose whether he wanted to participate in the religion of the foster family, and the foster family set limits to the extent he was allowed to express his original religion. Here, the child's right to autonomy is challenged.

Religious dilemmas also emerged regarding the topic of whether and how religious minority socialization for transreligiously placed foster children would need to be arranged. In a few cases, majority Dutch foster parents mentioned that they did not want to familiarize their foster children with Islam or Hinduism, as the only true faith for them was Christianity. Other foster parents, particularly those without a faith, thought it was useful for there to be some form of minority-religion socialization but said they felt ill-equipped to carry out this task. They therefore tried to facilitate religious socialization processes by buying religious holy books (e.g., the Qur'an) for the children or reaching out to external parties. For example, a foster parent explained how she had reached out to the city council to ask if there was a Muslim person in their area who would be willing to help out with Islamic socialization. However, from the foster children's stories, it proved quite difficult for Muslim or Hindu children to fully immerse themselves in Islam or Hinduism when they were living in a family without a religion. For example, abiding by Islamic praxis, such as five daily prayers, fasting, or learning Arabic for Qur'an reading, was hard when nobody 
else in their family shared this interest. This situation shows the profound challenges in religious identity formation that exist even when foster parents are willing and trying to live up to the article in the Convention on the rights of the child (1989) that emphasizes religious continuity during out-ofhome placements.

In one case, a Muslim foster child from an orthodox Islamic family was placed in a liberal Muslim foster family. He was critical of his foster mother, who would carry out activities on her own and also ask him to perform household chores. He perceived these actions and requests as conflicting with the proper ethnoreligious-inspired gender roles he had learned in his birth family. His foster mother responded with a lesson about gender equality and told him that in her family, differences between men and women did not exist. It was unclear whether the boy agreed.

\section{How Adherence to the New Faith of the Foster Family Influences the Foster Child's Relationship with Their Birth Family}

Almost all foster children who had a foster family with a religion that was new to them seemed to have gradually adopted the faith of their foster family (even when they had been raised with a different or no faith in their birth family). For example, a South Asian-Dutch boy, Anish, who had not been brought up with a faith in his birth family, said: "And yes... I believe (in God) now... if you hear stories from the bible, and if you want to stay in a Christian family... yes, then you will gradually start believing." This seemed to be the result of foster children simply joining in with "normal" family life, a common practice in foster care. Nevertheless, a need to blend in with their new family (i.e., the foster family) stimulated the adoption and maintenance of the new faith. For instance, a Christian foster mother explained how their non-religious foster child had wanted to join their religious family praxis of Christian prayers before going to sleep, as this was a family ritual and she wanted to be part of the family.

Our empirical data also showed a few examples of a communication breakdown related to religious issues or adolescents who started to perceive their birth parents as living a morally questionable life. For example, a foster child living with a conservative Protestant family (Bianca) gradually adopted a belief system corresponding with conservative Protestantism. This influenced her relationship with her birth mother, whom she visited regularly. Bianca started questioning her parents' substance abuse, for instance: "My foster parents asked me: What do you want do with your life? Do you want your life to go astray and messed up, or do you want do good?" Moreover, the birth mother had given Bianca jewelry with perceived "supernatural protective powers"; however, after she had discussed with her foster parents that only God can help you, rather than a material object, Bianca discarded the jewelry. This example shows the social gap emerging between children and their parents due to the adoption of the foster family faith. Furthermore, even in cases (also present in our datasets) where little or no contact existed between the foster child and birth family, it can be suspected that adoption of the foster family's faith may hinder future attempts by either the birth family or the foster child to reinitiate contact.

\section{Religious Identity Searches and the Need for Belonging Regarding Ethnoreligious Boundary Drawing}

Another topic that emerged concerned ethnic-minority foster children with a minority religion (in the cases retrieved, Islam) who lived with non-religious Dutch majority families and started to actively search for their religious identity in adolescence. These searches seemed to be influenced by an awareness of their ethnoreligious "differences" from their foster family and their desire to connect or reconnect with their ethnoreligious peers. In children's perceptions, their ethnic and religious identity often coincide. However, some foster children were perceived by their Muslim and co-ethnic peers, or even by extended family members, as inadequate or "fake" Muslims because they usually did not engage in all Islamic praxis, unlike their same-ethnoreligious peers or (extended) family. To illustrate, sometimes peers or extended family members pointed out to our informants (i.e. foster children) that did not qualify as Muslims because they chose not to abide by certain praxis: As a Somali-Dutch girl (Amira) explained:

It is hard... most the children at school are Muslim, and they expect me to follow the (Islamic) rules... and I say, well, I don't follow them, or well, I follow them in my own way (...) for example, soon it will be Eid (Islamic fasting), and many children in my class will join (the fasting)... but I am not sure if I want to, and then they see you as not a good Muslim.

Additional examples consisted of birth parents being disappointed that their children could not cite the Qur'an, or, in the case of a Muslim girl, the birth family argued that she trespassed Islamic chastity codes by socializing with male school peers. These examples show that a trans-religious placement can pose additional challenges for foster children and become a source of identity conflict for them. Hence, in trans-religious foster placements, there is a risk that the child's right to belong to their religious (and ethnic) birth group is negatively impacted by their rejection on religious 
grounds by members of their religious community of origin. Thus, the question arises of whether and how the impact of this rejection can be alleviated, considering foster children are a potentially vulnerable group due to severe childhood adversities. In most of these cases, foster parents of a majority background were either unaware of these issues or did not seem to know how to respond to them.

\section{Religious Traditions that Impact Bodily Integrity and Their Negotiation by Foster Parents, Birth Parents, and Foster Care Agencies}

Foster parents and birth parents could also disagree on religious rituals in which the birth parents wanted to involve their children but which raised concern among foster parents regarding the children's wellbeing. This situation, too, could create moral dilemmas. For example, in one case, foster parents stated that the Muslim mother of their foster child, Nesrin, wanted to have him circumcised for religious reasons when he was young, while the foster parents were against this practice, as they perceived this would violate his physical integrity. However, this was solved by the law on youth care. As the mother still had custody over the child, the foster parents had to comply with her wishes. Another case concerned the foster mother of Naima, a child of North African origin, who feared that his birth family would want the girl to be genitally cut, this being a common practice in their native country. Naima's foster mother put pressure on the foster agency to initiate a conversation with family to discuss and forbid this and then found that the parents said they had no intention of having Naima genitally cut. This reassured the foster mother, yet she was dismayed because she was the one who had to push the foster care agency to act.

\section{Discussion}

Through empirical examination, this study has identified and unpacked five moral dilemmas present in trans-religious foster care placements: (1) pressure from birth parents and foster parents to abide by their religious praxis; (2) objections from the foster family to the faith of the birth family; (3) a switch to the faith of the foster family by the foster child; (4) challenges to the religious identity searches of foster children due to ethnoreligious boundary drawing between majority and minority groups; and (5) the impact of religious traditions on the bodily integrity of foster children. We now discuss these dilemmas regarding ethical arguments to disentangle how the best interests of foster children growing up in a religiously non-matched placement can be safeguarded to provide them with healthy identity development. As stated previously, we prioritize children's interests over those of other stakeholders (birth parents and foster parents), although we also take the latter into account in our discussion.

First, our data showed that trans-religious placements may create pressure on foster children from birth parents or foster parents regarding abiding by religious praxis. Such pressure resulted in children attempting to be sensitive to the religious requests or praxes of both types of families. The religious requests and accompanying praxes of two families cannot always be easily reconciled. These complexities, influenced by religious differences, relate back to an extensive body of literature underpinning how foster children often worry about "fitting in" with their foster families, a feeling that may continue long after they arrive (Steenbakkers et al., 2018). Many foster children want to blend in more easily with their foster families and, possibly, their religious praxis. All children have the basic need to belong to a group (e.g., primarily the family with which they live) where they feel emotionally safe. However, foster children exhibit loyalties to their birth parents, even when they have received little protection and emotional support from them (Van Holen et al., 2020). It would be unfortunate if religious pressures from birth and foster families contribute to loyalty conflicts, as such conflicts are in turn associated with emotional and behavioral problems (Leathers, 2003). Hence, additional strains on the relationship with their birth parent(s) due to religious differences involved in trans-religious placement should be avoided.

A second dilemma we identified concerned tensions between the foster family's accommodation of, versus objection to, the faith of the birth family and how this impacts a foster child's identity and wellbeing. We found an example of a Hindu boy living in a Christian host family that forbade religious Hindu objects in their house, and a Christian family that disapproved of the jewelry the birthmother had given the child as a present. The birthmother of the Hindu boy keenly monitored his religious devotion, rendering it questionable whether such a match is recommendable in regard to a smooth identity development of the child. These cases seem to suggest that opting for the same religion is a safer and better match. Nevertheless, another case which emerged from our data was an ethnic and apparent religious match (both Muslim, with the same ethnic minority background). However, the foster child came from a birth family with an orthodox Islamic praxis, while the foster parents were more liberal Muslims. This circumstance underpins the work of Vertovec (2007), who showed that the ethnoreligious composition of immigrant populations in urban areas in the west has become "superdiverse" (Scholten et al., 2019; Vertovec, 2007). Due to an increasing variety of identity markers among immigrant populations (e.g., social class status, migration history, rural versus urban origin, gender, 
religious subgroups), these populations have witnessed "diversification of their diversity". Among young Muslims (as well as Christians), new pedagogies have emerged that emphasize personal conviction and piety, through which young people distinguish themselves from older generations within these faith traditions (Beekers, 2014). Thus, the notion of religious matching is more complicated than it seems at first sight. Even when religious backgrounds initially seem to correspond, further investigation is needed and, if differences prove to be present, ways to handle them should be discussed with the parents and foster family.

A third moral dilemma we found concerned children's adoption of the new faith of the foster family vis-à-vis their relationship with the birth family. All foster children in our study who had moved to a foster family with a different religion had adopted the new faith of their foster family or showed a keen interest in it. If participating in the foster family's religious traditions means the child adopting a new religion, this likely leads to social distancing between them and their birth parents, which may induce a breakdown in communication. This outcome does not benefit the child's wellbeing. We found evidence in the cases studied here of pressure from birth families as well as foster parents based on their religion. These pressure mechanisms may be detrimental to a foster child's wellbeing.

Furthermore, the question arises of whether foster children who adopt a new faith (i.e., that of their foster family) truly do so of their own free choice, as prescribed by Article 14 of the Covenant of the Civil and Political Rights of Children (Kilkelly, 2014), for which the Netherlands has declared its support. Some foster children may grow up in a limited context of choice-one that does not match what Kymlicka (1995) suggested is necessary for minorities to have a real option for choice. This outcome was particularly likely when the foster family pressured the child to follow their religious customs, such as attending church, while not giving the child space to, or not stimulating the child to keep up with, the birth parents' religion. A further complication is that this situation concerns minors who, traditionally, are believed to be not yet capable of autonomy. However, this idea is rapidly changing, as evidenced by different areas of law in which children have been given more right to decide for themselves than in the past, particularly in the case of adolescents (Hannan, 2019). Thus, based on these arguments, giving full attention to a foster child's voice would mean that foster parents should respect the foster child, who may want to continue adhering to the same religious (or atheist) beliefs that he or she was raised with, or, if he or she wishes, choose not to be religious any more or adopt a new faith (that may be different from that of his or her foster family). Nevertheless, the minors in our sample, even though they were predominantly adolescents (age 12 and older), were placed in their foster families when they were children (age $<10$ years), which is rather common among foster children. This fact complicates a straightforward understanding of their degree of self-autonomy as adolescents in foster care.

A fourth dilemma that we described in our results concerned religious identity searches (originating from a need for belonging) amid ethnoreligious boundary drawing. Identity questions-such as "who am I?" and "where do I belong?"- are always present in adolescence; however, trans-ethnoreligious placements may precipitate these questions in particular. We found evidence that when the ethnic and religious identities of foster children overlapped, as it does among Moroccan and Turkish Muslims in the Netherlands (Verkuyten \& Martinovic, 2014), these children were prone to be scrutinized and mocked as fake Muslims by same-ethnic peers or their extended family. Anti-Muslim sentiment in society, and the corresponding defensiveness within Muslim communities, has induced ethnoreligious boundary drawing between "Us and Them" (Van Bergen et al., 2017). A Muslim foster child who is removed from their ethnoreligious community faces double jeopardy: Islamophobia from the mainstream, and social exclusion by their ethnoreligious minority group. These affronts are additional burdens on their already complex identities as foster children (Degener et al., 2020; Pitcher \& Jaffar, 2018). Furthermore, our data showed that the foster children in this situation also seemed to be without foster family resources that could provide a defense against such ethnoreligious exclusion.

A final dilemma observed concerned religious traditions that impact bodily integrity and how managing these challenged foster parents, birth parents, and foster care agencies. We found cases of fear of practices threatening the physical integrity of the child. Jurisdiction can provide some answers to these dilemmas. If parents are still legal guardians, they can decide on male circumcision, since this practice is not illegal in the Netherlands (and other European countries).

\section{Limitations and Recommendations for Practice and Policy}

We did not have direct access to birth parents' views of these dilemmas regarding religious differences, as interviewing them proved difficult. Furthermore, the study had a relatively small sample size built from combining relevant interviews from archived datasets. Therefore, it is uncertain whether the saturation principles in qualitative studies have been met (Hiles \& Čermák, 2008).

Notwithstanding these limitations, this study has demonstrated that examining the religious identities and praxis of the child, birth family, and foster family should be part of 
the matching process before placement, and thus be a part of foster care workers' casework. Also, during placement, foster care workers should find out how the topic of religion has unfolded in the lives of all the parties involved, starting with the foster child. Furthermore, increased awareness and sensitivity are needed among foster parents regarding the pressure they put concerning religious adherence on foster children in trans-religious placements, as this can feed loyalty conflicts with birth parents. Foster parents should carefully navigate their desire to have the foster child participate in their religious praxis, as they should be mindful of not adding to the potential conflict of loyalty felt by the child. Additionally, ethnoreligious minority children need assistance with the double jeopardy of boundary drawing by in-and-out groups (Islamophobia and mistrust by minority groups). A recommendation regarding this would be for foster parents to seek out minority religious communities and religious peers, who are accepting their foster children, and inform them that they are Muslims, and others are not to be the judges of their religious identities.

\section{Conclusion}

In this study, we addressed moral dilemmas around how religion should be weighted in trans-religious foster care placements to provide foster children with healthy identity development. When moral dilemmas turn into conflicts, three guiding principles are relevant. First, foster children are entitled to expect reasonable efforts are made to accommodate their religious interests, especially older children (e.g., adolescents). Second, legal parents (often birth parents) are entitled to expect foster parents to make reasonable efforts to accommodate their religious preferences with regard to their children, especially with short-term placements. Third, foster parents should make reasonable efforts to accommodate the religious preferences of foster children and the legal parents if doing so does not infringe upon their own religious interests. In this paper, we particularly emphasize the foster child's perspective.

We conclude that it is in the child's best interests to have a foster family that, when making (some) religious choices on their behalf, is sensitive to the dynamic process whereby their personality and identity develop in relation to their religious ideas and beliefs. This implies that foster parents need to support the process of religious reflection and religious self-determinism in their foster children, especially when they enter adolescence. Furthermore, children have the right to be heard and informed about the religious praxis and conviction of their foster family before and during a placement, and this aspect is currently not given enough focus in Dutch foster care (Kilkelly, 2014; Pastor et al., 2020; Zeijlmans et al., 2017). Granting foster children these rights and being mindful of religious self-determinism is a concretization of their freedom of thought, conscience, and religion (Convention on the rights of the child, 1989).

Funding Funding was supported by zonmw (Grant No. 854011009).

Open Access This article is licensed under a Creative Commons Attribution 4.0 International License, which permits use, sharing, adaptation, distribution and reproduction in any medium or format, as long as you give appropriate credit to the original author(s) and the source, provide a link to the Creative Commons licence, and indicate if changes were made. The images or other third party material in this article are included in the article's Creative Commons licence, unless indicated otherwise in a credit line to the material. If material is not included in the article's Creative Commons licence and your intended use is not permitted by statutory regulation or exceeds the permitted use, you will need to obtain permission directly from the copyright holder. To view a copy of this licence, visit http://creativecommons.org/licenses/by/4.0/.

\section{References}

Allen, H., Garfinkel, I., \& Waldfogel, J. (2018). Social policy research in Social Work in the twenty-first century: The state of scholarship and the profession; What is promising, and what needs to be done. Social Service Review, 92(4), 504-547. https://doi.org/10. 1086/701198

Ammerman, N. T., (2007). Introduction: Observing religious modern lives. In Ammerman, N.T., (Ed.) Everyday religion: Observing modern religious lives. Oxford University Press.

Arnett, J. J. (Ed.). (2015). The Oxford handbook of emerging adulthood. Oxford University Press.

Convention on the rights of the child. (1989). Treaty no. 27531. United Nations Treaty Series (Vol. 1577, pp. 3-178). https://treaties.un. org/doc/Treaties/1990/09/19900902\%2003-14\%20AM/Ch_IV_ 11p.pdf. Accessed January 2022.

Bagci S. C. \& Rutland A. (2020). Ethnic majority and minority youth in multicultural societies. In Titzmann, P. F., \& Jugert, P. (Eds.). (2020). Youth in superdiverse societies: Growing up with globalization, diversity, and acculturation (Series Studies in adolescent development).

Bandura, A., \& McClelland, D. C. (1977). Social learning theory (Vol. 1). Prentice Hall.

Becci, I., Burchardt, M., \& Giorda, M. (2017). Religious super-diversity and spatial strategies in two European cities. Current Sociology, 65(1), 73-91. https://doi.org/10.1177/0011392116632030

Beekers, D. (2014). Pedagogies of piety: Comparing young observant Muslims and Christians in the Netherlands. Culture and Religion. https://doi.org/10.1080/14755610.2014.884009

Bell D. M. (2009). Religious identity. Conceptualization and measurement of the religious self. [Unpublished $\mathrm{PhD}$ Thesis], Emory University.

Bender, C. (2012). Practicing religions. In R. A. Orsi (Ed.), The Cambridge companion to religious studies (pp. 273-295). Cambridge University Press.

Bovenschen, I., Lang, K., Zimmermann, J., Förthner, J., Nowacki, K., Roland, I., \& Spangler, G. (2016). Foster children's attachment behavior and representation: Influence of children's pre-placement experiences and foster caregiver's sensitivity. Child Abuse \&amp; Neglect, 51, 323-335. 
Braun, V., \& Clark, V. (2006). Using thematic analysis in psychology. Qualitative Research in Psychology, 3(2), 77-101. https://doi.org/ 10.1191/1478088706qp063oa

Clayton, M. (2019). Children and political neutrality. In Gheaus, A., Calder, G., \& de Wispelaere, J (Eds). The Routledge handbook of the philosophy of childhood and children. Routledge.

Day, M., \& Bellaart, H. (2015). De rol van Etniciteit, Cultuur en Religie in de Pleegzorg. Een Verkenning. Verwey-Jonker Instituut. [Report in Dutch on the Role of Ethnicity and Religion in Dutch Foster Care]

Degener, C. J., van Bergen, D. D., \& Grietens, H. W. (2020). The ethnic identity complexity of transculturally placed foster youth in the Netherlands. Children and Youth Services Review, 113, 104957. https://doi.org/10.1016/j.childyouth.2020.104957

Degener, C. J., Van Bergen, D. D., \& Grietens, H. W. (2021). The ethnic identity of transracially placed foster children with an ethnic minority background: A systematic literature review. Children \&amp; Society. https://doi.org/10.1111/chso.12444

Hannan, S. (2019). Childhood and autonomy. In Gheaus, A., Calder, G., \& de Wispelaere, J (Eds). The Routledge handbook of the philosophy of childhood and children.

Hiles, D., \& Cermák, I. (2008). Narrative psychology. In C. Willig \& W. Stainton-Rogers (Eds.) The Sage handbook of qualitative research in psychology. (pp. 147-164.) Sage Publishers.

Jackson, L. J., White, C. R., O’Brien, K., DiLorenzo, P., Cathcart, E., Wolf, M., et al. (2010). Exploring spirituality among youth in foster care: Findings from the Casey Field Office Mental Health Study. Child \&amp; Family Social Work, 15(1), 107-117.

Jonker, M, Van Spaendonck, R., \& Tigchelaar, J. (2015) "Religie En Cultuur in Familierechtelijke Beslissingen Over Kinderen." Familie \& Recht. [article in Dutch: Religion and Culture in relation to Decisions in Family Law about Children]

Kennedy, J. C., \& Zwemer, J. P. (2010). Religion in the modern Netherlands and the problems of pluralism. Bmgn - Low Countries Historical Review, 125(2-3), 237-237. https://doi.org/10.18352/ bmgn-lchr.7121

Kilkelly, U. (2014). The child's right to freedom of religion in international law. In Fineman, M., \& Worthington, K. (Eds). What is right for children? The competing paradigms of religion and human rights. Ashgate.

Knibbe, K., \& Kupari, H. (2020). Introduction: Theorizing lived religion. Journal of Contemporary Religion, 35(2), 157-176. https:// doi.org/10.1080/13537903.2020.1759897

Kregting, J., Scheepers, P. L. H., Vermeer, P. A. D. M., \& Hermans, C. A. M. (2018). Why God has left the Netherlands: Explanations for the decline of institutional Christianity in the Netherlands between 1966 and 2015. Journal for the Scientific Study of Religion, 57(1), 58-79. https://doi.org/10.1111/jssr.12499

Kymlicka, W. (1995). Multicultural citizenship. Clarendon press

Leathers, S. J. (2003). Parental visiting, conflicting allegiances and emotional and behavioural problems among foster children. Family Relations, 52(1), 53-63. https://doi.org/10.1111/j.1741-3729. 2003.00053.x

Martin, D. (2017). On secularization: Towards a revised general theory.

McGuire, M. B. (2008). Lived religion: Faith and practice in everyday life. Oxford University Press.

Meyer, B. (2018). Frontier zones and the study of religion. Journal for the Study of Religion, 31(2), 57-78. https://doi.org/10.17159/ 2413-3027/2018/v31n2a3

Netherlands Statistics. (2020). Which faith do Dutch people adhere to? Downloaded in January 2022, from https://longreads.cbs.nl/neder land-in-cijfers-2020/welk-geloof-hangen-we-aan/

Palinkas, L. A., Horwitz, S. M., Green, C. A., Wisdom, J. P., Duan, N., \& Hoagwood, K. (2015). Purposeful sampling for qualitative data collection and analysis in mixed method implementation research. Administration and Policy in Mental Health and Mental Health Services Research, 42(5), 533-544. https://doi.org/10. 1007/s10488-013-0528-y

Pastor, C., Balsells, M. À., Vaquero, E., Mateo, M., \& Ciurana, A. (2020). Uninformed, afraid and confused: What children need to know at the beginning of their foster care process. Child Care in Practice. https://doi.org/10.1080/13575279.2020.1723065

Pitcher, D., \& Jaffar, S. (2018). 'To another's house': The experiences of Muslim young people in foster care. Adoption \&amp; Fostering, 42(3), 219-233. https://doi.org/10.1177/0308575918790437

Reimer, D., \& Schäfer, D. (2015). The use of biographical narratives to explain favourable and unfavourable outcomes for children in foster care. Adoption \&amp; Fostering, 39(1), 5-20. https://doi. org/10.1177/0308575914565084

Rushton, A., \& Minnis, H. (2008). Residential and foster family care. In M. Rutter, D. Bishop, D. Pine, S. Scott, J. Stevenson, E. Taylor, \& A. Thapar (Eds.), Rutter's child and adolescent psychiatry (pp. 487-501). Wiley Blackwell. https://doi.org/10.1002/9781444300 895.ch32

Scholten, P., Crul, M., \& Van de Laar, P. (2019). Coming to terms with superdiversity. Springer.

Scott, L. D., Munson, M. R., McMillen, J. C., \& Ollie, M. T. (2006). Religious involvement and its association to risk behaviors among older youth in foster care. American Journal of Community Psychology, 38(3-4), 223-236. https://doi.org/10.1007/ s10464-006-9077-9

Skivenes, M., Barn, R., Kriz, K., \& Pösö, T. (Eds.). (2014). Child welfare systems and migrant children: A cross country study of policies and practice. Oxford University Press.

Smith, J. F. (1996). Analyzing ethical conflict in the transracial adoption debate: Three conflicts involving community. Hypatia, 11(2), 1-33. https://doi.org/10.1111/j.1527-2001.1996.tb00662.x

Steenbakkers, A., Van Der Steen, S., \& Grietens, H. (2018). The needs of foster children and how to satisfy them: A systematic review of the literature. Clinical Child and Family Psychology Review, 21(1), 1-12. https://doi.org/10.1007/s10567-017-0246-1

Strolin-Goltzman, J., Kollar, S., \& Trinkle, J. (2010). Listening to the voices of children in foster care: Youths speak out about child welfare workforce turnover and selection. Social Work, 55(1), 47-53. https://doi.org/10.1093/sw/55.1.47

Tyrell, F. A., Marcelo, A. K., Trang, D. T., \& Yates, T. M. (2019). Prospective associations between trauma, placement disruption, and ethnic-racial identity among newly emancipated foster youth. Journal of Adolescence, 76, 88-98. https://doi.org/10.1016/j.adole scence.2019.08.010

Van Bergen, D. D., de Ruyter, D. J., \& Pels, T. V. (2017). "Us Against Them" or "All Humans Are Equal": Intergroup attitudes and perceived parental socialization of Muslim immigrant and native Dutch youth. Journal of Adolescent Research, 32(5), 559-584.

Van Holen, F., Clé, A., West, D., Gypen, L., \& Vanderfaeillie, J. (2020). Family bonds of foster children. A qualitative research regarding the experience of foster children in long-term foster care. Children and Youth Services Review, 119, 105539. https:// doi.org/10.1016/j.childyouth.2020.105593

Verkuyten, M., \& Martinovic, B. (2014). Minority identity and host national identification among immigrants. In C. K. W. D. Dreu (Ed.), Social Conflict Within and Between Groups (pp. 55-75). Psychology Press.

Vermeer, P. A. D. M. (2014). Religion and family life: An overview of current research and suggestions for future research. Religions, 5(2), 402-421. https://doi.org/10.3390/rel5020402

Vertovec, S. (2007). Super-diversity and its implications. Ethnic and Racial Studies, 30(6), 1024-1054. https://doi.org/10.1080/01419 870701599465

White, C., O’Brien, K., Jackson, L., Havalchak, A., Phillips, C., Thomas, P., \& Cabrera, J. (2008). Ethnic identity development 
among adolescents in foster care. Child and Adolescent Social Work Journal, 25(6), 497-515. https://doi.org/10.1007/ s10560-008-0140-2

Zeijlmans, K., López, M., Grietens, H., \& Knorth, E. J. (2017). Matching children with foster carers: A literature review. Children and Youth Services Review, 73, 257-265. https://doi.org/10.1016/j. childyouth.2016.12.017

Zeijlmans, K., López, M., Grietens, H., \& Knorth, E. J. (2018). "Nothing goes as planned": Practitioners reflect on matching children and foster families. Child \&amp; Family Social Work, 23(3), 458-465. https://doi.org/10.1111/cfs.12437

Publisher's Note Springer Nature remains neutral with regard to jurisdictional claims in published maps and institutional affiliations. 